\title{
EVOLUTION OF PERCUTANEOUS RENAL ACCESS
}

Mussammet D Ahmed and Ananda Kumar Dhanasekaran

Sandwell and West Birmingham NHS Trust, United Kingdom

Corresponding Author: Mussammet Ahmed Email: dinaahmed714@gmail.com

\begin{abstract}
Introduction: Nephrostomy insertion is a vital part of modern-day urology used to manage obstructed renal tract or gain percutaneous renal access.

Method: We carried out a PubMed literature search on the history of the development of nephrostomies. Results: The first percutaneous nephrostomy was performed in 1864 on a child who died in 5 years. Nephroscopy was then described and performed in 1941 during an open surgery with subsequent advancement to percutaneous nephrolithotomy in 1976 and antegrade stent insertion in 1978.

Conclusion: Clinical need and innovation have led to percutaneous renal access and subsequent stone treatment modality.
\end{abstract}

\section{BACKGROUND}

Innovations in technology and improvement in radiology have led to the evolution of techniques for renal access. From more morbid open renal access, we now also have in our armamentarium less morbid options, including antegrade renal access via nephrostomy and retrograde renal access via ureteroscopy.

Percutaneous nephrostomy is an interventional procedure indicated for urinary diversion (for obstruction due to intrinsic or extrinsic cause) or access to the renal collecting system (for infusion of therapeutic substances or endourological procedures). This paper will look at the evolution of percutaneous renal access since its first introduction in 1864.

\section{EVIDENCE SEARCH}

Data were obtained from PubMed, ClinicalKey, and Google Scholar literature search with the terms 'history' or 'evolution' of 'nephrostomy' or 'percutaneous renal access' with no time period restrictions. We also reviewed the Handbook of Endourology. Limited papers were available to date and have been reviewed to illustrate the history of percutaneous renal access.

\section{EVOLUTION OVER TIME}

\section{Discovery of nephrostomy}

Percutaneous nephrostomy was first described in 1865 by Dr. Thomas Hillier (Figure 1) in London. He was a physician at Great Ormond Street Hospital for Sick Children. He treated a 4-year-old boy named Johnny Ross with a hydronephrotic kidney, whom he believed was congenitally obstructed. ${ }^{1-8}$

The boy had abdominal distension at birth which was thought to be ascites until age 4, when it was ascertained to be a cyst in the right lumbar region. The enormous size of this cyst caused him difficulty in breathing and walking. Hence, in 1864, this was tapped anteriorly with 102 ounces ( $\sim 3$ litres) of fluid drained with characteristics of dilute urine. This reaccumulated rapidly and led to multiple further taps (from 1864 to 1868 ) both anteriorly and posteriorly, with attempts to create a permanent fistula for drainage. It was eventually postulated that this boy had a congenital malformation of his right ureter, which caused an intermittent obstruction. The child was finally admitted to the hospital for possible further tapping but became febrile and died on $5^{\text {th }}$ August 1868 


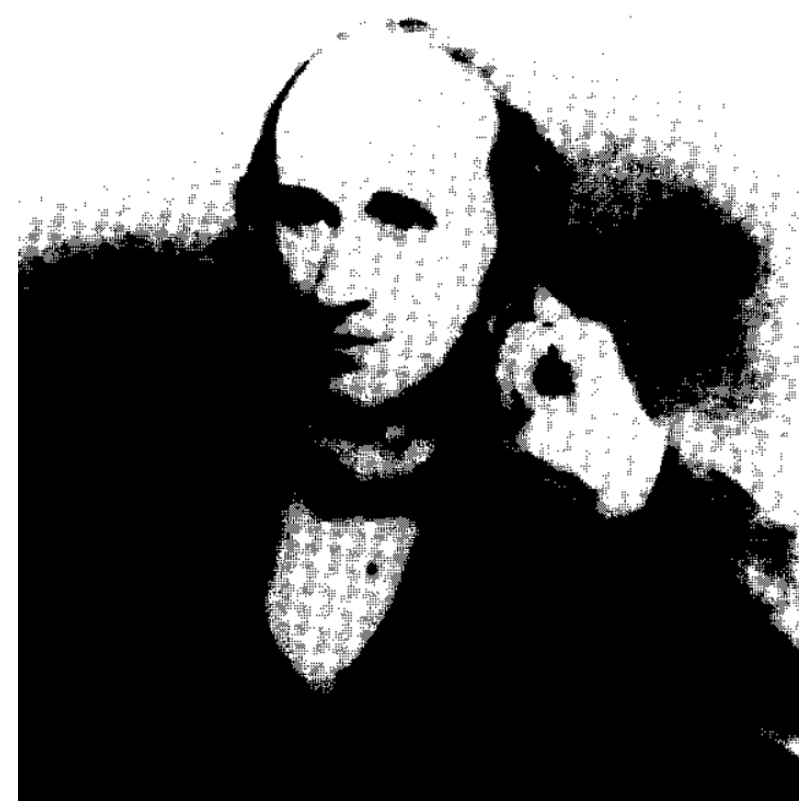

Figure 1. Dr. Thomas Hillier, Great Ormond Street Hospital for Sick Children, 1831-1869.

(age 8) with no clear documentation of whether further drainage was performed. Post mortem examination probably performed by Dr. Hillier himself confirmed that the presumed cyst was a hydronephrotic kidney secondary to pelviureteric obstruction and subsequent death due to an obstructing distal ureteric stone in the opposite kidney.

Dr. Hillier was not given his due recognition for his contribution to discovering percutaneous renal access. This may have been partly due to his untimely death in 1868 due to hemoptysis from pulmonary tuberculosis. As a result, percutaneous renal access did not gain any further popularity until the 1950s.

\section{Discovery of nephroscopy}

In 1941, Dr. Ernest Rupel (Figure 2) and Robert Brown first described nephroscopy. ${ }^{2}$ They reported a case of a 44-year-old lady who presented with general malaise, right-sided abdominal and back pain, with a history of the intermittent passage of 'white stuff' in her urine over several years. She was found to have bilateral renal stones and had a previous history of removal of gallstones, appendix, and eventually her gallbladder.

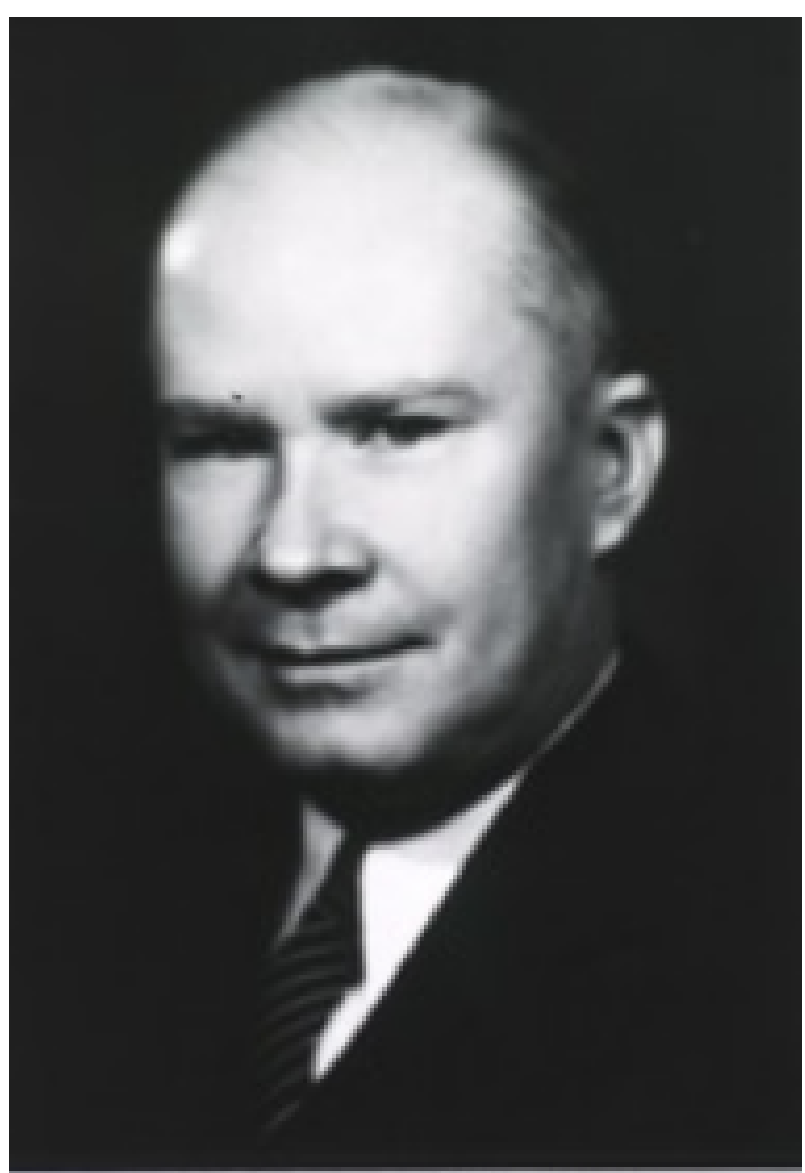

Figure 2. Dr Ernest Rupel. Images from US national library of Medicine Digital collection https://collections.nlm.nih.gov/catalog/nlm:nlmuid-101428070-img

When she presented in March 1941, she underwent cystoscopy and retrograde examination (Figure 3), which demon-strated a hydronephrotic non-functioning right kidney containing a complete staghorn calculus and multiple small calculi. In addition, there was evidence of caliectasis and pyelectasis. The left kidney was functional with normal renal pelvis and calyces but contained a $1.6 \mathrm{~cm} \times 0.8 \mathrm{~cm}$ calculus.

The right side was hence treated with a nephrectomy. On readmission with anuria and subsequent failure to pass catheter beyond left pelviureteric junction she eventually underwent nephrostomy insertion (using 26F catheter) to ensure drainage from her now solitary kidney (Figure 4).

Thirteen days later, after clinical improvement, she was due to have open surgery for left renal calculus 


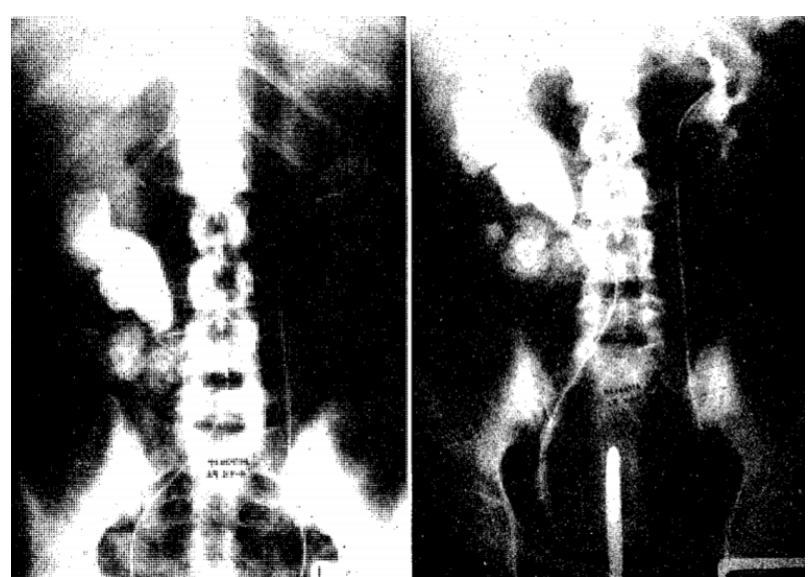

Figure 3: Cystoscopy and bilateral retrograde studies.

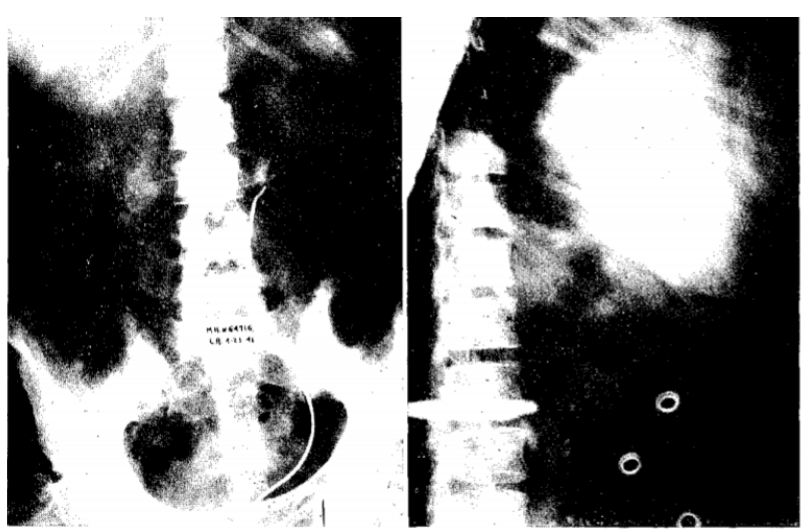

Figure 4. Attempted retrograde left ureteric catheter insertion.



Figure 5. (Left) Utility Forceps; (Right) Surgical wound.

extraction. Instead, Rupel and Brown proceeded with the trial of nephroscopy by exchanging the $26 \mathrm{~F}$ catheter for an $18 \mathrm{~F}$ catheter, passing a pan-endoscope through the catheter, and successfully removing the stones using utility forceps (Figure 5 shows the forceps used and the wound). An $18 \mathrm{~F}$ catheter was reinserted at the end of the procedure and successfully removed 2 days later, and the patient clinically improved.

This was the first reported use of nephrostomy access for nephroscopy and removal of renal calculi.

\section{The first antegrade nephrostogram leading to a series of nephrostomies}

Willard Goodwin (Figure 6) was a renowned urologist and the first Chairman of the Department of Urology at the University of California, Los Angeles (UCLA). In 1955 he placed a needle into a hydronephrotic kidney while performing a renal arteriogram and injected some contrast into the collecting system, thereby performing the first antegrade nephrostogram. ${ }^{3}$ He concluded the procedure by placing a tube to drain the kidney. This was the first antegrade nephrostomy tube insertion.

The same year Goodwin et al. reported a series of percutaneous nephrostomies in 16 patients. ${ }^{4,8}$ Sixteen patients had eighteen procedures. In 5 patients, the procedure failed due to insufficient needle length or inability to access the pelvicalyceal system. In three cases, drainage stopped after a short period of days. A further four cases ended with nephrectomies when it was determined that drainage did not improve renal function, thus implying poorly functioning/non-functioning kidneys. Finally, in 4 cases (two bilateral), this proved successful in providing temporary relief of obstruction, allowing nephron-sparing treatment opportunity at a later date to restore normal antegrade urine flow. In his paper, he described the following complications and contraindications demonstrated in Table 1. 


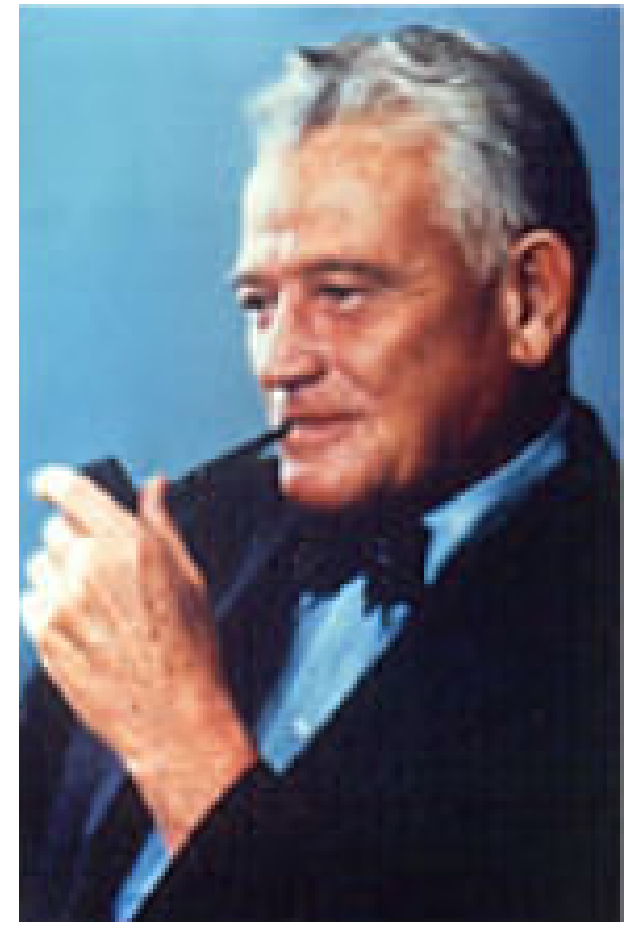

Figure 6. Dr. Willard Goodwin.

This was the first reported series of nephrostomy insertions where five cases failed due to technical difficulties, few moribund patients died within 3 days, and a postmortem examination suggested death occurred due to pre-existing progressive uremia. Other deaths occurred in weeks to months from causes unrelated to the nephrostomy insertion. In addition, the benefit of temporary drainage was demonstrated in selected cases of large hydronephrosis, but this method was not used again until the 1970s.

\section{Re-discovery of nephroscopy to percutaneous nephrolithotomy and antegrade stents}

In the 1970s nephroscopy was rediscovered but as part of open surgery. The technique involved mobilising the kidney, followed by the introduction of a nephroscope (Figure 7) or paediatric panendoscope via a pyelotomy. The advantage of this technique was that both the kidney and nephroscope could be manipulated to view all the renal calyces. Needless to say, this was a traumatic technique for renal stone treatment. Hence in 1976, Fernstrom and Johansson
Table 1. Complications and Contra-Indication Noted from Dr Goodwin's Series

\begin{tabular}{|l|l|}
\hline COMPLICATIONS & CONTRAINDICATION \\
\hline infection & uremia \\
\hline bleeding & coagulopathy \\
\hline blocked tube & tuberculosis \\
\hline kinking of tube & malignancy \\
\hline intermittent blockage & \\
\hline inadequate drainage & \\
\hline
\end{tabular}

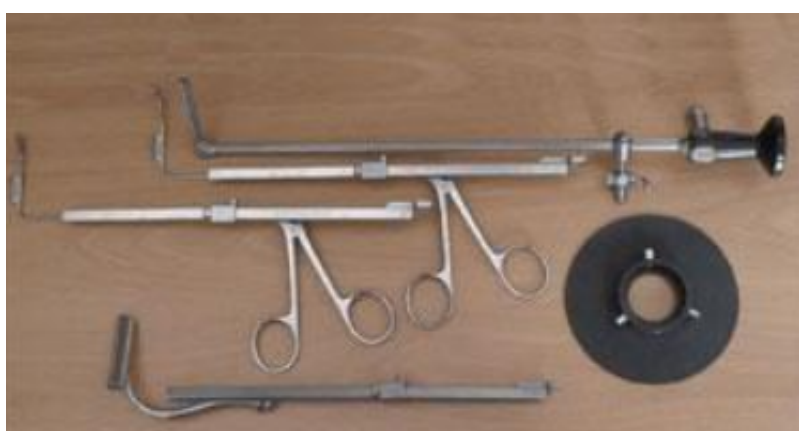

Figure 7. Nephroscope used in the 1970s. Courtesy: BAUS Virtual Museum.

described renal stone extraction via percutaneous nephrostomy under radiological guidance. ${ }^{5,8}$

In 1978, the first antegrade ureteric stent insertion was performed by Arthur Smith ${ }^{3,6}$ (Figure 8). Author of Smith's Textbook of Endourology, he emigrated to the United States from South Africa in 1977. The following year, he performed ureteric reimplantation in a patient who developed unilateral ureteric obstruction secondary to prostate cancer. This patient developed a postoperative anastomotic leak in which he could not stent retrograde due to the position of the uretero-cystostomy. Hence he planned and introduced a Gibbons stent into the reimplanted ureter through a percutaneous nephrostomy. On this occasion, he gained percutaneous access, passed a catheter down into the bladder, attached a stent to the end of the catheter, and subsequently pulled up the stent to the kidney (Figure 8b). This was the next advancement from nephrostomy insertion to antegrade stent insertion and led to the establishment of renal and ureteric access from below and above. The antegrade approach has evolved further since its discovery; stents are passed 



Figure 8. (a) Dr Arthur Smith (b) diagram of 1st antegrade approach to stent by Dr Arthur Smith Courtesy: (a) Legends in Urology, The Canadian Journal of Urology, Oct 2011 (5). (b) Endourological society website (video presentation)

down through the nephrostomy rather than pulled up from the bladder.

Dr. Smith worked along with Dr. Bob Miller (a talented radiologist and pioneer of interventional radiology) (Figure 9) and progressed the application of percutaneous renal access to insertion of circle tubes (inserted via a second nephrostomy puncture in patients with indwelling nephrostomy tubes that became blocked or dislodged). The application was further extended to antegrade chemolysis using acetylcysteine and sodium bicarbonate for cystine stones and then renacidin for struvite stones. Unfortunately, it took a couple of weeks of continuous irrigation to dissolve the stone and, as such, was not very economical. Dr. Smith also collaborated with Dr. Ralph Clayman (Figure 10) who initially favoured open surgery for stones and later became one of the prominent developers of minimally invasive surgery.

\section{Establishment of the endourology society and popularisation of percutaneous access}

Dr. Smith formulated the term 'endourology,' first used in the Journal of Urology in $1979^{7}$ to describe 'closed controlled manipulation of the genitourinary tract.' His residents and sceptics would mock this as 'end of the urology' due to diversion from already established open surgery. He subsequently collaborated with an interventional radiologist and inventor, Kurl Amplatz which led to many innovations in percutaneous nephrolithotomy (PCNL). ${ }^{6}$ Percutaneous access soon became the preferred option over open nephrostomy. Dr. Amplatz had a laboratory technician who could rapidly create the instruments requested. Hence their concept of dilating nephrostomy tracts to remove renal calculi led to the development of Amplatz dilators and then Amplatz sheaths and advanced PCNLs. Dr. Arthur Smith also formed the first Endourology Society before the third World Congress on 


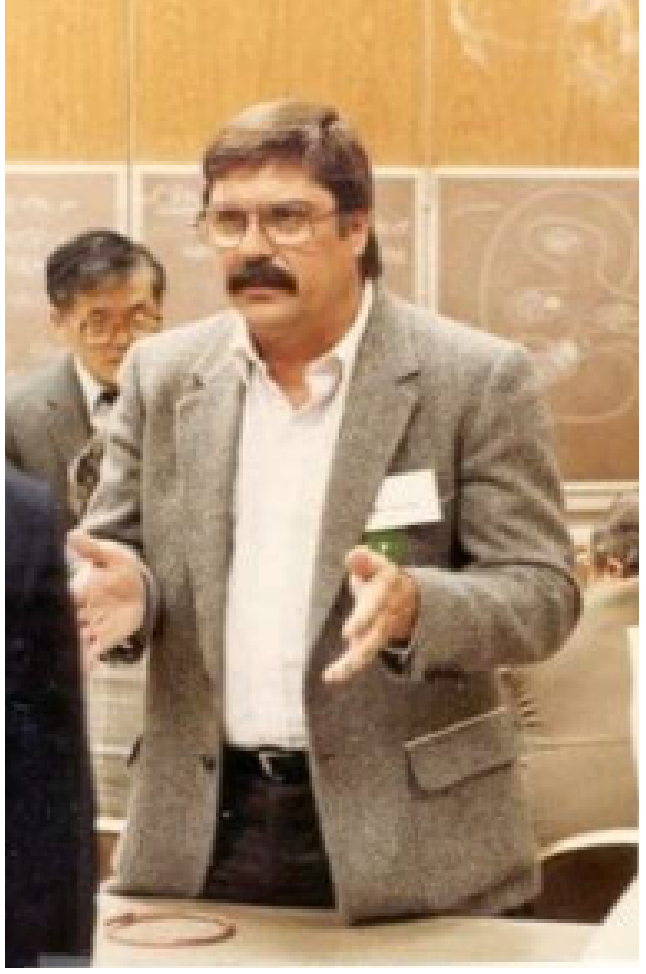

Figure 9. Dr Bob Miller.

Courtesy: COOK Medical Website.

Endourology along with Dr. Segura, Dr. Badlani, and Dr. Clayman (Figure 11). He was the founding president, Dr. Ralph Clayman the secretarygeneral, Dr. Segura the vice president, and Dr. Badlani, the treasurer.

Percutaneous pyelolithotomy was eventually popularized in the 1980s in Great Britain by Wickham and Kellet and in Germany by Alken. Over the years, the indications of this technique and procedure also diversified from the drainage of the obstructed kidney to gaining access for stone treatment, chemolysis, or administration of other therapeutic agents. It was eventually included in the American Urology Association (AUA) guidelines in 2005 as the first-line treatment recommendation for staghorn stones. ${ }^{9}$

\section{Nephrostomy - supporting armamentarium of endourologist}

The role of nephrostomies and percutaneous access has been established and recognised in guidelines. It is performed both by urologists and interventional radiologists. In the United Kingdom, this is predominantly

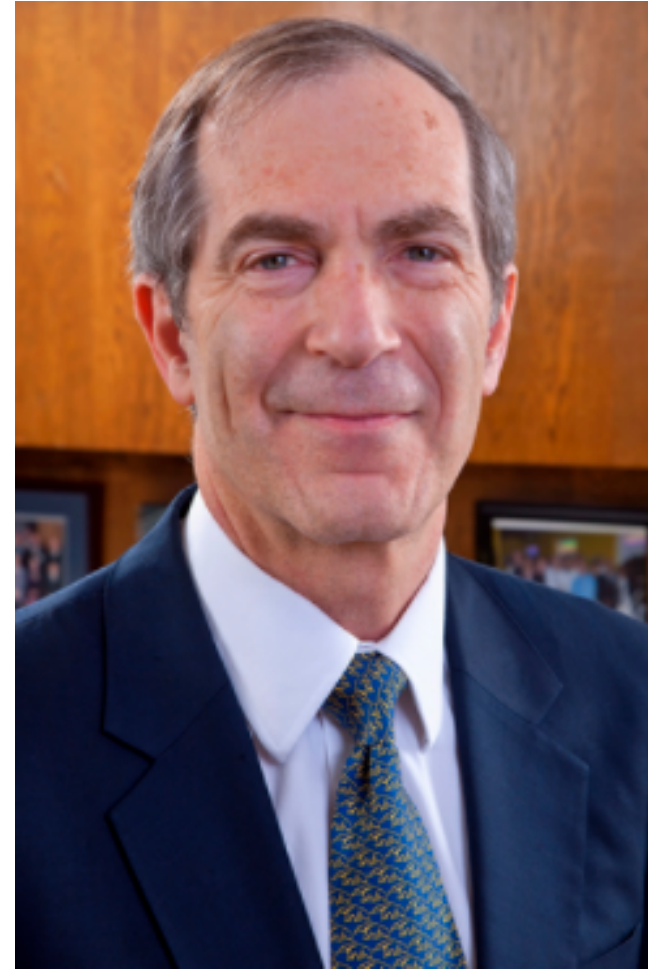

Figure 10. Dr Ralph Clayman.

Courtesy: University of California San Francisco Website



Figure 11: (left to right) Dr. Segura, Dr. Badlani, Dr. Arthur Smith, and Dr. Clayman formed the first Endourology Society before the 3rd World Congress on Endourology; endourological society. 
done by radiologists and is increasingly being undertaken by urologists. The latter is more so for the percutaneous renal access for elective stone treatment (nephrolithotomy) while interventional radiologists primarily undertake elective and emergency primary nephrostomy insertions. Evidence supports the role of urologists in gaining percutaneous access under ultrasound guidance. ${ }^{10} \mathrm{~A}$ study from Greece involving 650 nephrostomy insertions by urology consultants and registrars performed under local anaesthetic reported a 30-day major complication rate of 3.3\% and minor complication rate of $4.5 \%$. This concluded that ultrasound-guided nephrostomy insertion by urologists is safe and efficient.

\section{CONCLUSION}

Clinical need and innovation have led to establishing percutaneous renal access and subsequent percutaneous stone treatment modality. It is now an essential armamentarium in endourology and is included in guidelines for stone treatment. Apart from establishing and advancing techniques of renal access, over time, there have also been advancements in adjunct technology such as lasers to widen the modalities at our disposal. Percutaneous renal access is a skill shared by interventional radiologists and urologists, with evidence supporting the latter as safe and efficient.

\section{DISCLOSURE}

No conflicts declared.

\section{REFERENCES}

1. Morgan J, Scardino L, Thomas Hillier MD, et al. Percutaneous Nephrostomy. Available at: https:// kundoc.com/pdf-thomas-hillier-and-percutaneousnephrostomy-.html
2. Rupel E, Brown R. Nephroscopy with the removal of stone following nephrostomy for obstructive calculous anuria. J Urol 1941;46:177-18. Available at: https:// kundoc.com/pdf-nephroscopy-with-removal-of-stonefollowing-nephrostomy-for-obstructive-calculou.html

3. Patel SR, Nakada SY. The modern history and evolution of percutaneous nephrolithotomy. J Endourology 2015;29(2):153-7. doi: 10.1089/end.2014.0287. Epub 2014 Sep 17.

4. Goodwin WE, Casey WC, Woolf W. Percutaneous trocar (needle) nephrostomy in hydronephrosis. J Am Med Assoc 1955;157(11):891-94.

5. Fernstrom I, Johansson B. Percutaneous pyelolithotomy. A new extraction technique. Scand J Urol Nephrol 1976;10:257-59.

6. The Canadian Journal of Urology. Legends in Urology - Dr Smith. Can J Urol 2011;18(5). Available at: https://www.canjurol.com/html/free-articles/V18I502-Legends_DrSmith.pdf

7. Cook Medical Website. Early Courses Helped Shape Endourology. [Internet]. Available at: https://www.cookmedical. com/urology/early-courses-helped-shape-endourology/

8. Georgescu D, Multescu R, Geavelete B. Percutaneous Surgery of Upper Urinary Tract, Handbook of Endourology. 2016. Available at: https://doi.org/10.1016/ B978-0-12-802404-1.00001-3

9. Preminger GM, Assimos DG, Lingeman JE, et al. Chapter 1 AUA guidelines on the management of staghorn calculi: diagnosis and treatment recommendations. J Urol 2005;173(6):1991-2000.

10. Skolarikos A, Alivizatos G, Papatsoris A, et al. Ultrasound guided percutaneous nephrostomy performed by urologists: 10 year experience. Urology 2006;68(3):495-9. doi: 10.1016/j.urology.2006.03.072. Epub 2006 Sep 18.

J Endolum Endourol Vol 4(2):e29-e35; August 19, 2021.

This article is distributed under the terms of the Creative Commons AttributionNon Commercial 4.0 International License. (c) Ahmed and Dhanasekaran. 